\title{
A new species of Homalocerus Schoenherr from the Atlantic coast of the State of São Paulo, Brazil (Coleoptera, Belidae, Belinae), with notes on color pattern and on the sclerites of the internal sac
}

\author{
Sergio A.Vanin ${ }^{1}$ \\ ${ }^{1}$ Departamento de Zoologia, Instituto de Biociências, Universidade de São Paulo, Caixa Postal 26077, 05513-970 São Paulo-SP, Brasil. \\ savanin@ib.usp.br

\begin{abstract}
A new species of Homalocerus Schoenherr from the Atlantic coast of the State of São Paulo, Brazil (Coleoptera, Belidae, Belinae), with notes on color pattern and on the sclerites of the internal sac. Homalocerus bimaculatus sp. nov. (type locality: Brazil, São Paulo) is described and illustrated, and comments on the sclerites of the internal sac of aedeagus and on color pattern are provided. The new species is compared to other similar species of the genus, being distinguished by having three clusters of carmine pubescence on pronotum and two lateral whitish oval spots located slightly before the middle of each elytron. Six species of Homalocerus, including the new one, are known from the State of São Paulo. The previously published identification key for species of Homalocerus is updated to include H. bimaculatus.
\end{abstract}

KEYWORDS. Atlantic Forest; Insecta; male genitalia; Neotropical Region; weevil.

During a visit carried out in October 2011 to the weevil collection of the Department of Entomology, National Museum (Národní Muzeum), Prague, Czech Republic (NMPC), I found one unidentified specimen of the belid Homalocerus Schoenherr, 1839. Dr. Jiř́ Hájek, curator of the beetle collection, has kindly lent me his unique specimen which, after a closer examination, proved to be a new species. Homalocerus was revised by Vanin (1976). No new species have been described since then and the genus currently includes eight species (Vanin 1976; Wibmer \& O'Brien 1986). With the addition of the new species described herein, the total number of species of Homalocerus rises to nine. Six species of Homalocerus, including the new one, are represented in the Atlantic Forest region of the State of São Paulo: $H$. bimaculatus, sp. nov., $H$. longirostris Vanin, 1976, H. lyciformis (Germar, 1833), $H$. nigripennis Boheman, 1839, H. plaumanni Voss, 1937, and H. xixim Bondar, 1947.

\section{MATERIAL AND METHODS}

Measurements and proportions, line drawings and the taxonomic description follow Vanin (1976). The morphological terminology was updated according to Lawrence et al. (2010, 2011). To avoid damaging the single available specimen, the procedure for extracting the male genitalia (Vanin 1976) was modified as follows. After softening the specimen in hot water for a few minutes, it was hold with dorsal side up with a forceps, under stereomicroscope. The elytra were gently opened and a hooked pin was inserted between the connective membranes of the last tergite and ventrite. The last tergite with male genitalia and stuck tissues were carefully extracted with another forceps and placed in a hot solution of $10 \% \mathrm{KOH}$, for one minute. Then, the abdomen tip was rinsed in distilled water, and the remaining soft tissues removed with a hooked pin under the steromicroscope. Finally, the tegmen was detached from the median lobe. Temporary slides were mounted in $100 \%$ glycerin. Drawings were made using a stereomicroscope Wild M5A and a microscope Leitz SM-Lux, both fitted with a camera lucida. The male genitalia and associated structures were stored in a microvial with a drop of glycerin and attached to the pin of the specimen. Photographs of the adults were taken in a stereomicroscope Leica M125 with coupled Magnifier in DV camera Leica DFC.

\section{TAXONOMY}

\section{Homalocerus bimaculatus sp. nov.}

(Figs. 1, 4, 7-9)

Description. General aspect (Fig. 1). Length $=11.0 \mathrm{~mm}$ (rostrum excluded). Head black, antennae testaceous. Pronotum with three areas of carmine pubescence. Elytra black, with two lateral, postmedian, oval spots of whitish pubescence.

Head. Integument rugose, black, with one cluster of sparse yellowish-white pubescence in front of eyes and one cluster behind eyes. Frons with deep fovea and one longitudinal, short, shiny carina. Rostrum (male) dark reddish brown, lighter near apex, 0.8 times shorter than pronotum, curved, cylindrical, slightly thicker at base than at apex; rugose, sculpture formed by coarse and deep punctures, coalescent at base, and becoming thinner and shallower towards apex; dorsally 

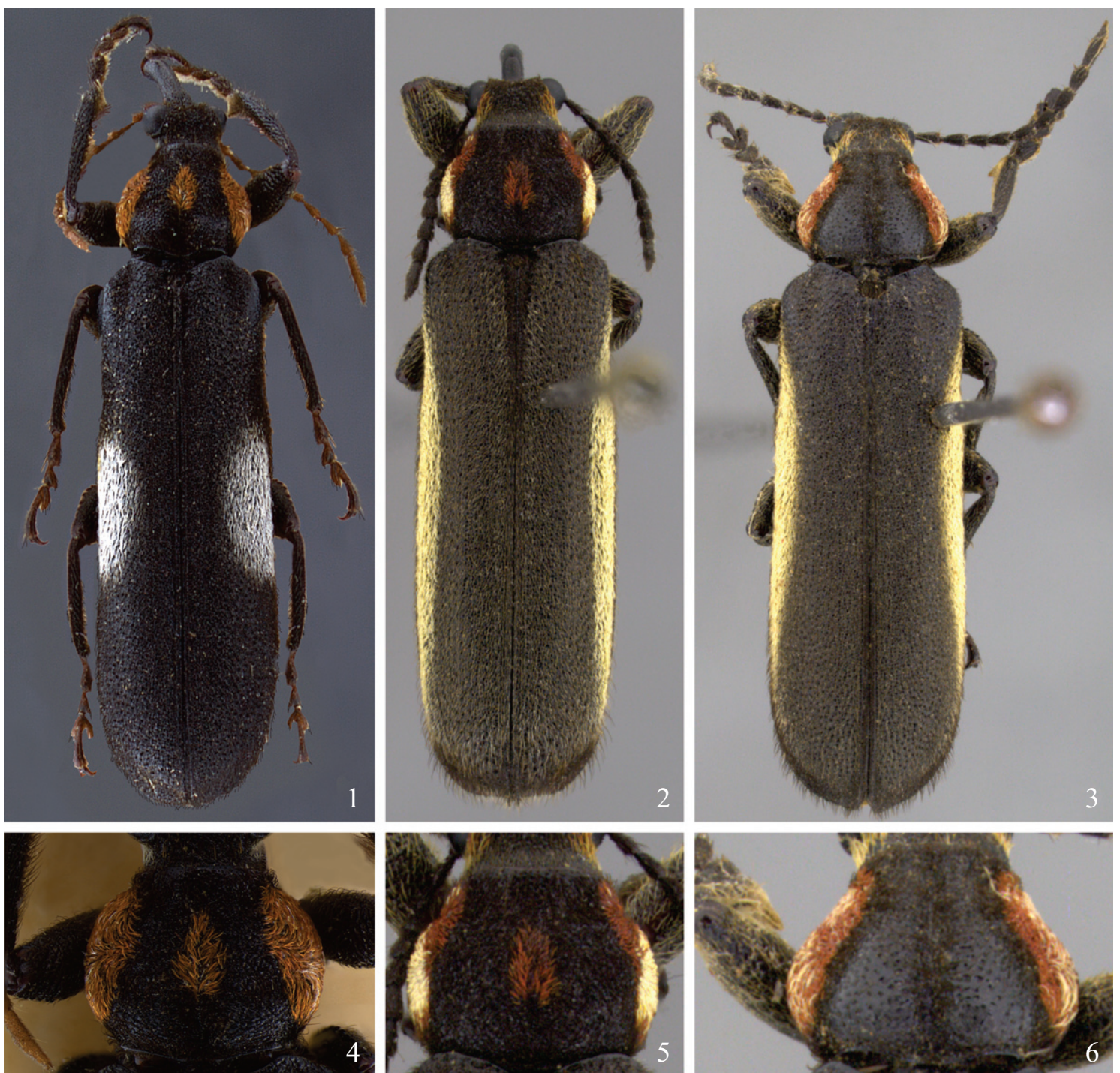

Figs. 1-6. Homalocerus spp., dorsal habitus and pronotum, respectively. 1 and 4, H. bimaculatus, holotype. (length = 11.0 mm); 2 and 5, H. nigripennis (from Rio de Janeiro, RJ; length = $10.0 \mathrm{~mm}$ ); 3 and 6, H. plaumanni (from Nova Teutônia, SC; length = $11.1 \mathrm{~mm}$ ).

with a band, narrow, impunctate and shiny; ventrally with sparse yellowish-white setae at base. Antennae with antennomere $\mathrm{XI}$ as long as two preceding ones together.

Pronotum transverse (Fig. 4), about 1.2 times as wide as long, inflated, sides rounded, constrict at apex, widest near middle, with a weak impressed median, longitudinal depression, deeper posteriorly; black, with three spots of depressed carmine pubescence, two lateral with a few sparse yellowish-white setae, and one, smaller and median; setae of lateral spots curved inwards and those of median spot directed forwards and outwards; integument coarsely rugose, posterior areas near median sulcus tumified.

Scutellum black, with sparse brownish setae.

Elytra (Fig. 1) 3.0 times as long as wide at humeri, and 4.0 times as long as pronotum; sides almost parallel in anterior half and slightly expanded towards apices; apices conjointly rounded; integument rugose, formed by large and small granules, irregularly distributed; black, except dark reddish brown margins; pubescence brownish, fine and sparse, more elongate and erect backwards; each elytron with one elongate oval spot of decumbent, whitish pubescence directed backwards, located laterally, slightly before the middle of each elytron; sutural region weakly elevated.

Ventral face. Integument of pro- meso- and metasternum, and ventrites, with whitish sparse pubescence. Legs dark reddish brown, tarsi lighter, with brownish fine and sparse setae.

Male genitalia. Aedeagus (Figs. 7-9). Penis tubular, curved, about 4.1 times as long as wide (struts of penis excluded); penis about 1.25 times as long as struts; pedum and tectum partially fused, tectum free only on apical third, forming an elongate sclerite over osteal region; internal sac with a long guide sclerite, ribbon-like, forming a pre-apical looplike projection when viewed in profile (Figs. 8,9 ) and ending in one bidentate sclerite (Fig. 7); flagellum not examined (see remarks); integument of internal sac coated with numerous and evenly distributed microtrichiae. 

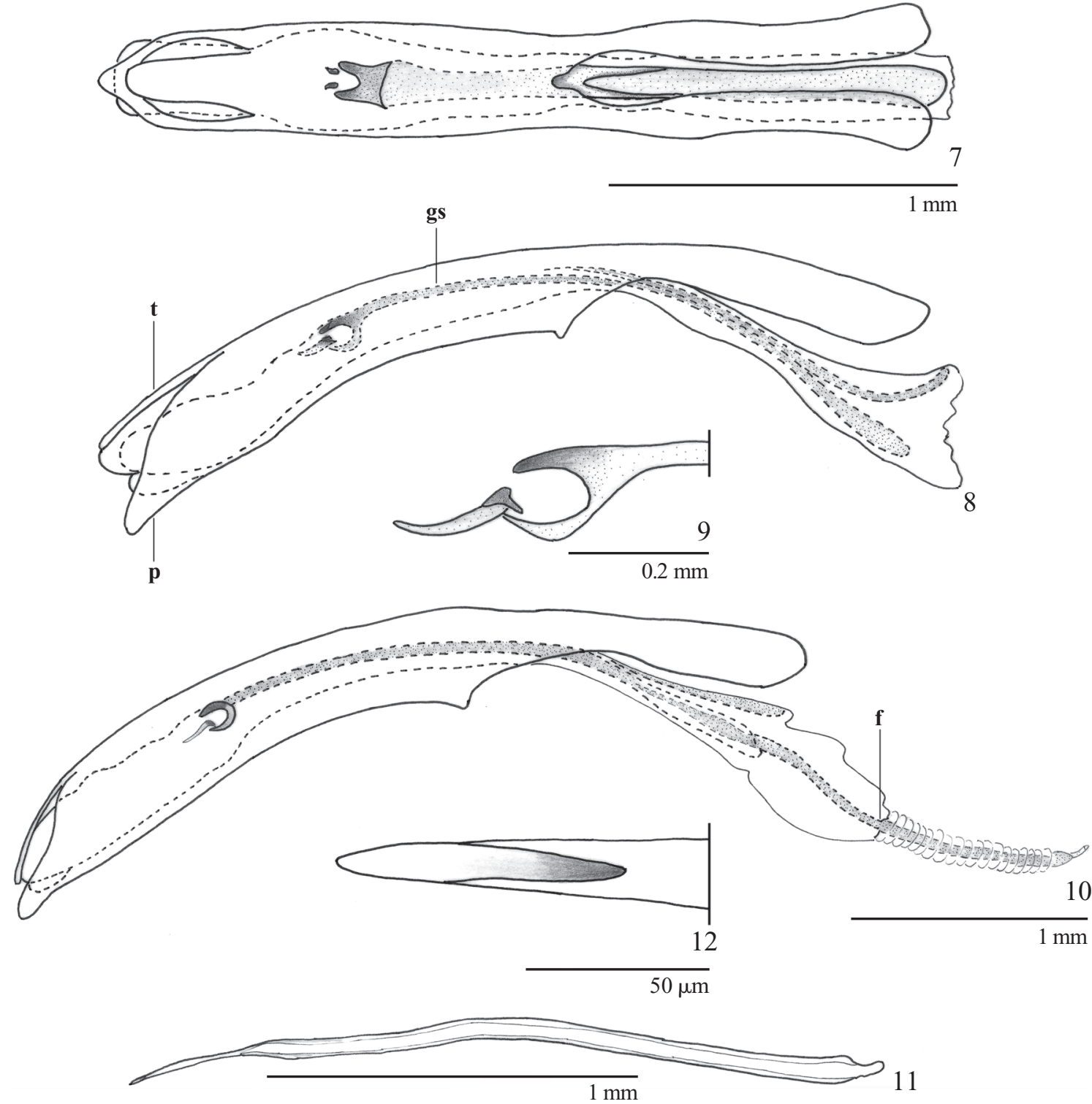

Figs. 7-12, Homalocerus spp., male genitalia. 7-9, H. bimaculatus, sp. nov, holotype. 7 and 8, aedeagus, dorsal and lateral views, respectively; 9, detail of apex of guide sclerite, lateral view. 10-12, H. lyciformis. 10, aedeagus (from Itatiaia, RJ), lateral view; 11, flagellum of internal sac (from Nova Friburgo, RJ); 12, detail of apex of flagellum. (f, flagellum; gs, guide sclerite; p, pedum; t, tectum).

Etymology: "bimaculatus", Latin, adjective that refers to the two whitish elytral spots.

Type locality: BRAZIL. São Paulo. Exact locality not specified.

Geographic distribution: State of São Paulo, Brazil (see Discussion).

Type material: Holotype male, "SÃO PAULO/BRAS. MRÁZ LGT/ MUS. PRAGENSE”, dissected (NMPC).

The key to species of Homalocerus (Vanin 1976: 25) should be modified as follows to include the new species:

3(1). Elytra black with two lateral, longitudinal bands of yellowish-white pubescence 4 - Elytra without longitudinal bands 5a(3). Elytral pubescence varying from yellowish-white to yellow, sometimes forming a transverse or oblique band in the median third, or, on the other extreme, covering the two basal thirds

- Elytral pubescence forming two lateral, whitish, oval spots located slightly before the middle of each elytron (Fig. 1)

H. bimaculatus sp. nov.

\section{DISCUSSION}

Homalocerus bimaculatus is unique among the other eight known species of the genus regarding the color pattern, being promptly distinguished by having two lateral whitish oval spots located slightly before the middle of each elytron and three clusters of carmine pubescence on pronotum (Figs. 1, 
5). The new species is similar to H. nigripennis (Figs. 2, 5), both species sharing a similar globose prothorax with three pronotal spots of scales. Rarely the pronotum of $H$. nigripennis has only two spots (Vanin 1976). In $H$. nigripennis, the two lateral spots on pronotum are formed by a dense cluster of yellowish pubescence surrounded by carmine setae, while in the new species the spot is formed mostly by carmine setae with only a few sparse yellowish-white setae. Besides, the elytral apices of $H$. nigripennis have a sharp spine at the sutural angle, but are conjointly rounded in $H$. bimaculatus. Homalocerus bimaculatus may also be confused with $H$. plaumanni (Figs. 3, 6), but the latter has the antennae black instead of testaceous and has only two lateral spots on pronotum instead of three; besides, H. plaumanni has the longitudinal sulcus of pronotum much more impressed and the pronotal spots with more yellowish-white setae interspersed among the carmine ones.

The pedon and tectum partially fused to a tubular penis, as seen in H. bimaculatus (Figs. 7, 8) and H. lyciformis (Fig. 10), is a feature of all genera of the tribe Belini (Kuschel \& Leschen 2003), not occurring in other Belidae, except in the oxycorynine genus Oxycraspedus Kuschel (Marvaldi et al. 2006; Anderson \& Marvaldi 2013). The sclerites of the internal sac, although had been seen in some species of Homalocerus, were neither described nor represented in the illustrations provided by Vanin (1976). These sclerites were studied and illustrated by Zimmerman (1994) in his book on the Australian Belidae, and were also used as character data by Kuschel \& Leschen (2003) in their analysis of the phylogenetic relationships among the genera of Belinae. However, the first illustrations of the male genital sclerites of a species of Homalocerus are presented herein. In the genus Homalocerus, the internal sac has a guide sclerite and a rigid basal sclerite or flagellum (Kuschel \& Leschen 2003). As the flagellum is more basally located in the internal sac, it was not extracted during the dissection of the male genitalia of the holotype of $H$. bimaculatus, remaining inside the abdomen. Thus, I am providing an illustration of the complete internal sac of $H$. lyciformis, the type species of the genus Homalocerus (Figs. 10-12). The flagellum of H. lyciformis is about as long as the length of the penis (struts excluded), narrows abruptly near the apex (Fig. 11) and has an oblique opening (Fig. 12). Homalocerus xixim has a very similar flagellum. The guide sclerite is very alike in all examined species of the genus $(H$. bimaculatus, H. lyciformis, H. plaumanni, H. nigripennis and H. xixim). The armature of the internal sac of Homalocerus resembles that of other Belinae, as for example of Isacanthodes monilis (Newman, 1838) and Leptobelus tibialis (Blackburn, 1893), illustrated by Zimmemann (1994: 350, fig. 231 and 356 , fig. 235 , respectively).

The printed label affixed to the holotype of $H$. bimaculatus, the single known specimen of the new species, do not provide any information about a more accurate locality than "São Paulo" (State of São Paulo). According to Dr. Jiř́i Hájek (NMPC), it is impossible to find a more precise information about the collecting locality of the holotype collected by Jaro
Mraz. Dr. Hájek informed that Jaro Mraz (1880-1927) lived in São Paulo at the beginning of the 20th century, and collected more than 300,000 insects, mostly beetles, for the National Museum of Prague. The material was originally well labeled, including accurate data about localities and habitat, but this information was subsequently lost and all Mraz's specimens have the same printed label as the one reported for the holotype of H. bimaculatus (Jiří Hájek, pers. comm.). The genus Homalocerus is predominantly distributed in the Brazilian Atlantic Forest, from south Bahia to northern Rio Grande do Sul. Only two species, H. lyciformis and H. xixim, were also recorded from a few localities far away of the main range (Vanin 1976). Considering the area of occurrence of the other species of Homalocerus in the State of São Paulo, the type of H. bimaculatus was most probably collected somewhere along the Atlantic Forest, near the coast.

Vanin (1976) commented on the two main aposematic color patterns observed in Homalocerus, one formed by a black body with transverse and longitudinal yellow stripes, and the other by a black elytra with two lateral, narrow, light bands of whitish scales, and a dark pronotum with two or three spots formed by carmine or carmine and yellowish scales (Figs. 2, 3). The former pattern is similar to that occurring in many lycids, and the latter in lampyrids of the genus Ethra Laporte, 1833 (cited by Vanin 1976 as Aethra Agassiz, 1846, currently being considered a junior synonym). The color pattern of Homalocerus bimaculatus differs from both described above, although it partially agrees with the "lampyroid pattern" in regard to pronotum (Figs. 4-6). Some adult species of Cantharidae are aposematic and have paired tergal glands, which produce repugnatorial compounds that reduce their palatability (Ramsdale 2002). At least two cantharid species, Chauliognathus fenestratus (Perty, 1830) (Chauliognathini) and Discodon tricolor (Guerin, 1844) (Silini) have a color pattern very similar to that of H. bimaculatus: black elytra with two lateral, postmedian, translucent, whitish oval spots, and a black pronotum with two lateral reddish and yellowish spots (Gabriel Biffi, pers. comm.). I collected C. fenestratus in the State of São Paulo (Estação Biológica de Boracéia, Salesópolis), during the day, sitting still on the surface of low vegetation, a common behavior displayed by aposematic insects. In the collections of the MZSP, C. fenestratus is well represented by several specimens and is found along the coast of southeastern Brazil, in areas of rainforest, from the states of Rio de Janeiro and Minas Gerais south to Santa Catarina, and D. tricolor occurs in the states of Rio de Janeiro and São Paulo. Homalocerus bimaculatus may belong to a mimetic complex, into which the palatable weevil would resemble the unpalatable models $C$. fenestratus and $D$. tricolor. Further field observations and studies should be carried out to support or reject this hypothesis.

\section{ACKNOWLEDGMENTS}

I would like to thank Dr. Jiří Hájek (Department of Entomology, National Museum, Prague, Czech Republic), for his assistance during my visit to the NMPC collection, for lend- 
ing the specimen used in this study, and for information about the Czech collector Jaro Mraz; Dr. Ricardo Pinto da Rocha (Instituto de Biociências, Universidade de São Paulo) for providing access to his photo equipment (FAPESP 2008/ 06604-7); M.Sc. Gabriel Boffi (MZSP) for information concerning the cantharid beetles; M.Sc. Daniela de Cassia Bená and M.Sc. Juarés Fuhrmann (IB and MZ, USP) for the sterosmicroscope photos and, respectively, for inking the line drawings and for assistance with the electronic editing of figures; Ricardo Pires Vanin for the digital processing of the photographs; and, two anonymous reviewers for suggestions that improved the paper.

\section{REFERENCES}

Anderson, R.S. \& Marvaldi, A.E. 2013. Finding unexpected beetles in odd places: Archicorynus kuscheli Anderson and Marvaldi, a new genus and species representing a new tribe, Archicorynini, of Oxycoryninae (Coleoptera: Belidae) from Nicaragua. The Coleopterists Bulletin 67: 61-71.

Kuschel, G. \& Leschen, R.A.B. 2003. Phylogenetic relationships of the genera of Belinae, p. 48-55. In: Kuschel, G. 2003. Nemonychidae, Belidae, Brentidae (Insecta: Coleoptera: Curculioinidae). Fauna of New Zealand 45: 1-100.
Lawrence, J.F., Beutel, R.G., Leschen, R.A.B. \& Slipiński, A. 2010. Glossary of morphological terms, p. 9-20. In: Leschen, R.A.B., Beutel, R.G. \& Lawrence, J.F. (Eds). Handbook of Zoology, Arthropoda: Insecta, Coleoptera, Beetles (Morphology and Systematics (Elateroidea, Bostrichiformia, Cucujoidea partim). Vol. 2, Berlin, Walter de Gruyter, 786 p.

Lawrence, J.F., Slipiński, A., Seago, A.E., Thayer, M.K., Newton, A.E. \& Marvaldi, A.E. 2011. Phylogeny of the Coleoptera based on morphological characters of adults and larvae. Annales Zoologici 61: 1-217.

Marvaldi, A.E., Oberprieler, R.G.,.Lyal, C.H.C., Bradbury, T. \& Anderson, R.S. 2006. Phylogeny of the Oxycoryninae sensu lato (Coleoptera: Curculionoidea) and evolution of host-plant associations. Invertebrate Systematics 20: 447-476.

Ramsdale, A.S. 2002. 64. Cantharidae, p. 201-218. In: Arnett, R.H., Jr., Thomas, M.C., Skelley, P.E. \& Frank, J.H. (eds.). American Beetles. Vol. 2, Polyphaga: Scarabaeoidea through Curculionoidea. Boca Raton, CRC Press, xiv+861 p.

Vanin, S.A. 1976. Taxonomic revision of the South American Belidae (Coleoptera). Arquivos de Zoologia 28: 1-75.

Wibmer, G.C. \& O'Brien, C.W. 1986. Annotated checklist of the weevils (Curculionidae sensu lato) of South America (Coleoptera: Curculionoidea). Memoirs of the American Entomological Institute 39: 1563.

Zimmerman, E.C. 1994. Australian Weevils. Volume 1. Orthoceri. Anthribidae to Attelabidae. The Primitive Weevils. Melbourne, CSIRO, xxxii+741 p. 